\title{
A platform for locoregional T-cell immunotherapy to control HNSCC recurrence following tumor resection
}

\author{
Shay Sharon ${ }^{1}$, Jason R. Baird², Shelly Bambina², Gwen Kramer², Tiffany C. Blair ${ }^{2,3}$, \\ Shawn M. Jensen ${ }^{2}$, Rom S. Leidner ${ }^{2}$, R. Bryan Bell ${ }^{2}$, Nardy Casap ${ }^{1}$, Marka R. \\ Crittenden $^{2,4}$ and Michael J. Gough ${ }^{2}$ \\ ${ }^{1}$ Department of Oral and Maxillofacial Surgery, Hadassah and Hebrew University Medical Center, Jerusalem 9112001, Israel \\ ${ }^{2}$ Earle A. Chiles Research Institute, Robert W. Franz Cancer Center, Providence Portland Medical Center, Portland, OR 97213 , \\ USA \\ ${ }^{3}$ Department of Molecular Microbiology and Immunology, Oregon Health and Sciences University, Portland, OR 97239, USA \\ ${ }^{4}$ The Oregon Clinic, Portland, OR 97213, USA \\ Correspondence to: Michael J. Gough, email: michael.gough@providence.org
}

Keywords: head and neck cancer; T-cell; immunotherapy; biomaterial; intratumoral

$\begin{array}{lll}\text { Received: April 19, } 2021 & \text { Accepted: May 26, } 2021 & \text { Published: June 22, } 2021\end{array}$

Copyright: ( 2021 Sharon et al. This is an open access article distributed under the terms of the Creative Commons Attribution License (CC BY 3.0), which permits unrestricted use, distribution, and reproduction in any medium, provided the original author and source are credited.

\section{ABSTRACT}

Surgical resection of head and neck squamous-cell carcinoma (HNSCC) is associated with high rates of local and distant recurrence, partially mitigated by adjuvant therapy. A pre-existing immune response in the patient's tumor is associated with better outcomes following treatment with conventional therapies, but improved options are needed for patients with poor anti-tumor immunity. We hypothesized that local delivery of tumor antigen-specific T-cells into the resection cavity following surgery would direct $\mathbf{T}$-cells to residual antigens in the margins and draining lymphatics and present a platform for T-cell-targeted immunotherapy. We loaded $T$-cells into a biomaterial that conformed to the resection cavity and demonstrated that it could release T-cells that retained their functional activity in-vitro, and in a HNSCC model in-vivo. Locally delivered T-cells loaded in a biomaterial were equivalent in control of established tumors to intravenous adoptive T-cell transfer, and resulted in the systemic circulation of tumor antigen-specific T-cells as well as local accumulation in the tumor. We demonstrate that adjuvant therapy with anti-PD1 following surgical resection was ineffective unless combined with local delivery of T-cells. These data demonstrate that local delivery of tumor-specific T-cells is an efficient option to convert tumors that are unresponsive to checkpoint inhibitors to permit tumor cures.

\section{INTRODUCTION}

Tumor-positive surgical margins are one of the most important risk factors for recurrence following surgical resection of HNSCC. Local recurrence develops even in patients who have histologically negative margins, and occurs at a high rate in patients with intermediate and highrisk features [1]. This observation suggests that residual tumor cells are often present following surgery, which leads to locoregional recurrence despite clear margins.

Adjuvant chemo/radiotherapy represents a partial solution to this problem [2], but there may also be a role for immunotherapy which is recently being evaluated in the neoadjuvant setting $[3,4]$. Enhancing tumor-specific immune responses at the time of the initial procedure will be valuable for control of residual microscopic disease, and to direct immune cells against distant tumor deposits [5]. Adoptive therapy of tumor antigen-specific T-cells is a proven approach to control metastatic disease in selected patients, and is generally delivered intravenously. Following adoptive transfer, T-cell expansion and in-vivo differentiation into tumoricidal effector cells is essential for effective therapy [6-8]. Secondary proliferation of transferred T-cells occurs in tumor-draining lymph nodes [7], meaning that adoptively-transferred cells are dependent on ongoing tumor antigen cross-presentation for full functional capacity. 
These data present a significant problem in the use of adoptive T-cell therapy for high-risk patients to treat minimal residual disease following surgery. In this scenario, there may be a narrow timeframe following surgical resection to successfully expand T-cells in-vitro, before cross-presented antigen is lost from the tumordraining lymph node [9]. Therefore, it would potentially be advantageous to rapidly direct transferred T-cells to the tumor-draining lymph node for in-vivo expansion, before cross-presentation of tumor-derived material is lost. One approach to achieve this is to load the T-cells into the tumor-draining lymphatics via local delivery, to give the maximum chance of meeting cognate antigen on antigen-presenting cells to permit in-vivo expansion. By contrast, systemically applied T-cells are likely to evenly distribute between tissues and secondary lymphoid organs throughout the patient while their target antigen is restricted to a specific lymphatic drainage system. This may result in an immediate reduction in the proportion of transferred cells that can meet their cognate antigen in the narrow time window [10].

The tumor resection cavity can be a poorly defined and disrupted site for the local delivery of cells and drugs. Biomaterials can serve as a vehicle to physically support agents in the resection cavity and permit locoregional delivery [11] of innate adjuvants in preclinical models of HNSCC [12] and other cancers [13]. Importantly, T-cells can be incorporated into biomaterials for locoregional delivery $[14,15]$, and combined with additional T-cell activating agents to improve tumor control [16, 17]. We propose that biomaterial delivery of T-cells to the resection site will naturally deliver these cells into contact with residual cancer cells or into the lymphatic drainage for expansion and recirculation to prevent local recurrence. We demonstrate in preclinical models that biomaterial-loading preserves T-cell function in-vitro and in-vivo, and in a surgical model of HNSCC results in control of tumor recurrence. Importantly, we show that adjuvant therapy with anti-PD1 fails to impact local recurrence unless combined with local delivery of tumor-specific T-cells, demonstrating that this approach has the potential to help patients with poor pre-existing anti-tumor reactivity. Together, these data demonstrate relevant locoregional immunotherapy with the potential to overcome locoregional recurrence for the benefit of highrisk HNSCC patients, and integration with conventional therapies.

\section{RESULTS}

\section{In-vitro characterization of T-cells loaded in a biomaterial}

Matrigel represents a convenient laboratory hydrogel that is a liquid when chilled, but solidifies into an amorphous solid at body temperature. This permits rapid local conformation of the loaded biomaterial to the unique shape of the resection cavity following surgery [12]. To function as a T-cell delivery system, it is critical that loaded T-cells retain their function over the course of biomaterial degradation and cell release. To study the dynamics of T-cells loaded into a biomaterial, $\mathrm{CD}^{+}$ T-cells were isolated from naïve C57/BL6 mice and introduced into Matrigel to form pellets (Figure 1A). After 2, 6, 12 and 24 hours the culture supernatant and Matrigel were isolated and the number of viable T-cells in each compartment was determined. The T-cell pellet rapidly degraded in culture (Figure 1B), and analysis of the pellet and supernatant revealed that the number of T-cells in supernatant increased over time while the number of T-cells in the pellet decreased over time, suggesting the sustained release of T-cells from the biomaterial during this timeframe (Figure 1Ci). Despite the absence of antigen or T-cell growth factors, there was no consistent difference in viability between T-cells in the biomaterial or in the culture supernatant (Figure 1Cii). To test the functionality of the released T-cells, we used an assay that could assess control of cancer cell growth by T-cells being released from the pellets over time. We coated wells with Moc1-ova cells engineered to express the model antigen SIINFEKL as a fusion protein to ensure non-secreted cytoplasmic protein expression (Moc1-ova). These cells were later overlaid with a Matrigel pellet that was loaded with OT1 cells specific for SIINFEKL, 2C T-cells with irrelevant specificity, or no T-cells. Wells were imaged at 2-hour intervals, and the confluency of the cancer cells in replicate wells was determined as previously described [18]. OT1 cells loaded into a biomaterial significantly decreased the confluency of Moc1-ova cells compared to 2C T-cells, or unloaded biomaterial ( $p<0.01$ ) (Figure 1D). Together, these data demonstrate that T-cells loaded into Matrigel undergo a sustained release in-vitro and are functionally active against cancer cells expressing their target antigen.

\section{Tumor control following intratumoral injection of antigen-specific T-cells}

To determine whether biomaterial loaded T-cells would control a tumor in-vivo, we evaluated direct intratumoral (IT) delivery. As a comparison to conventional adoptive transfer approaches, we also evaluated the systemic delivery of T-cells alone via IV injection. Moc1-ova tumors were established in immunecompetent C57BL/6 mice that were also injected with three doses of anti-CD40L, which blocks the anti-tumor immune response following tumor implantation (not shown). This approach results in tumors that lack preexisting anti-tumor immunity and are poorly responsive to conventional therapies [19], and is a model for patients who may most benefit from the transfer of tumor-specific T-cells. Mice were randomized to receive IV or IT adoptive 
T-cell transfer, and as a control for the invasiveness of intratumoral injection, mice were randomized to receive tumor antigen-specific OT1 T-cells or non-specific 2C T-cells. In this way, the tumors treated with OT1 versus $2 \mathrm{C}$ cells differ only in the TCR of the transferred cells, providing a highly relevant control treatment. $1 \times 10^{6}$ tumor-specific OT1 or non-specific 2C T-cells were administered intravenously in suspension, or loaded into Matrigel and injected into the tumor (Figure 2Ai). IT administration of OT1 T-cell-loaded biomaterial resulted in tumor growth delay compared to IT administration of $2 \mathrm{C}$ T-cell controls, demonstrating that T-cell function was retained in-vivo (Figure 2Aiii). IV administration of OT1 T-cells also resulted in transient tumor growth delay (Figure 2Aii); neither approach was curative, and there was not a significant difference in overall survival between
OT1 T-cells administered via IV versus IT transfer (Figure 2B), suggesting that local biomaterial delivery was equivalent in efficacy to conventional IV transfer. These findings underscore the potential of local delivery of T-cells into the tumor, achieving local control rates that are equivalent to the corresponding intravenous therapy.

\section{Characterization and phenotyping of circulating T-cells following adoptive T-cells transfer}

To evaluate whether IT transfer resulted in effective release and recirculation of tumor antigen-specific T-cells, we examined peripheral blood of treated animals to identify the number and phenotype of the transferred T-cells (Figure 3Ai). Adoptively transferred T-cells could be distinguished by congenic markers, allowing

A T cell biomaterial loading and in vitro culture

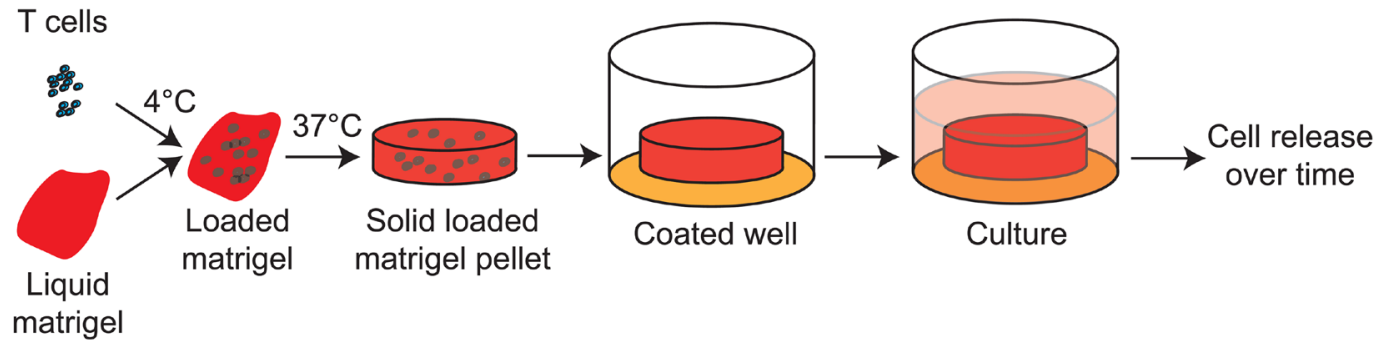

B In vitro biomaterial degradation

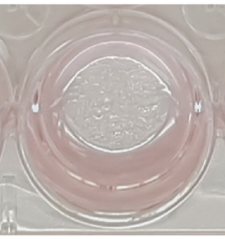

Coated well

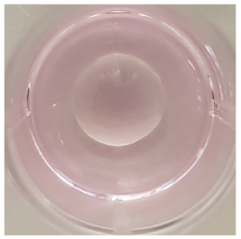

Pellet placement

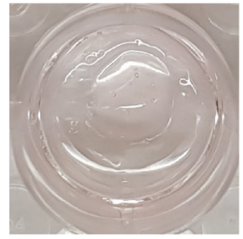

2hr culture

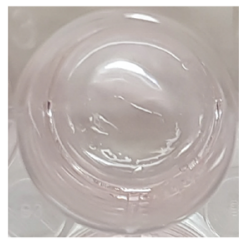

$6 \mathrm{hr}$ culture

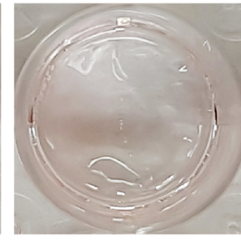

$12 \mathrm{hr}$ culture

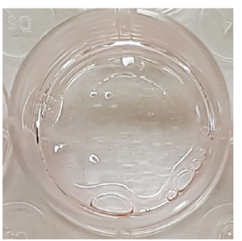

$24 \mathrm{hr}$ culture
C

i) T cell release

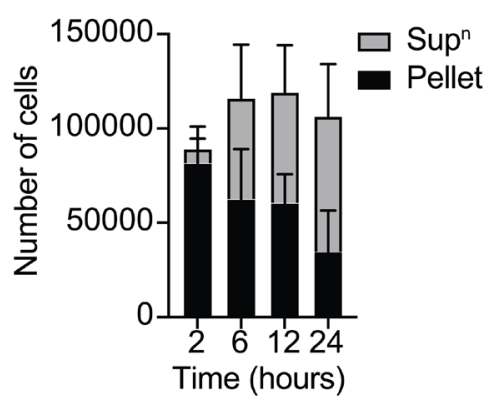

ii) T cell viability

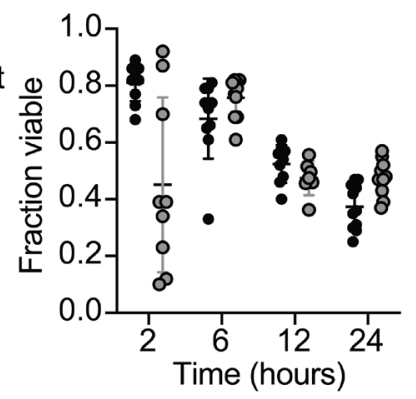

D Antigen-specific tumor control

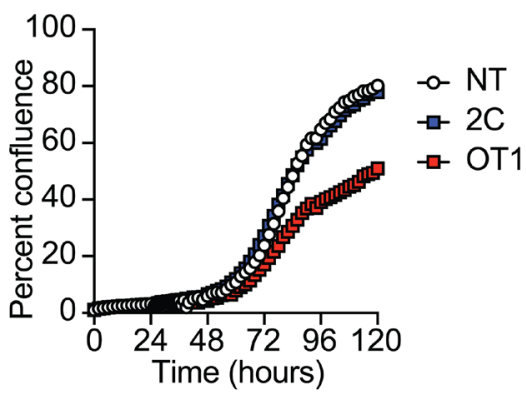

Figure 1: Biomaterial loading of T-cells. (A) Matrigel pellets containing purified CD8 T-cells from naïve C57BL/6 mice were seeded to 24 well Matrigel-coated plates and covered with media. (B) Images show placement and degradation of the pellet over time. (C) Culture supernatant and Matrigel were isolated over time and the number of viable T-cells in each compartment weredetermined. Graphs show (i) number of T-cells in supernatant and pellet over time, (ii) viability of T-cells in the supernatant and pellet over time. (D) Functional response of loaded T-cells. The well was coated with Moc1 cells engineered to express the model antigen SIINFEKL (Moc1-ova), and the Matrigel pellet was loaded with OT1 T-cells specific for SIINFEKL, 2C T cells with irrelevant specificity, or no T-cells (NT). Graph shows confluency of cancer cells over time. 
the identification of circulating $\mathrm{CD}^{+} \mathrm{CD} 8{ }^{+} \mathrm{CD} 90.1^{+} \mathrm{OT} 1$ T-cells and $\mathrm{CD}^{+} \mathrm{CD}^{+} \mathrm{CD} 45.1^{+} 2 \mathrm{C}$ T-cells (Figure $3 \mathrm{Aii}$ ). As expected, tumor antigen-specific OT1 T-cells were present in significantly higher numbers than non-specific 2C T-cells, and the OT1 T-cells declined in number over time (Figure 3B). Loss of these cells from the peripheral circulation broadly correlated with tumor progression, where tumors in all OT1 transferred mice had resumed growth over the 14-21 days period following transfer (Figure 2). To determine whether local delivery altered the differentiation of T-cells, we evaluated the expression of CD44 and CD62L tumor antigen-specific T-cells to identify differentiation into $\mathrm{CD} 44^{+} \mathrm{CD} 62^{-}$effector, CD $44^{+} \mathrm{CD}^{2} 2 \mathrm{~L}^{+}$memory, or CD44-CD62 $\mathrm{L}^{+}$naïve T-cells. Following both IV and IT treatment, both effector and memory populations were observed; however, effector cells were more rapidly lost from peripheral circulation and the small residual circulating population at later timepoints was mostly memory T-cells (Figure 3C). There was not a significant difference in the number or phenotype of OT1 T-cells that had been delivered via biomaterial injection into the tumor versus conventional IV delivery, suggesting that local delivery into a tumor environment does not impair T-cell function.

\section{Characterization of the tumor environment following injection of T-cell biomaterial}

To determine whether biomaterial delivery resulted in functional T-cell accumulation in the tumor, we examined the tumor immune environment 7 days following IT treatment, at the peak of tumor control. Tumors were harvested, bisected, and analyzed in parallel for T-cell infiltration by multiplex IHC and flow-cytometry. IHC analysis demonstrated that tumors treated with OT1loaded biomaterials exhibited a less defined organization compared to the more clearly defined structure of the 2C specimens (Figure 4A). Notably, in the OT1-injected samples, $\mathrm{CD}^{+} \mathrm{CD}^{+}$cells were located throughout the tumor, while $\mathrm{CD}^{+} \mathrm{CD}^{+}$cells in the $2 \mathrm{C}$-injected samples were mostly confined to stromal regions. Quantitative analysis showed $\mathrm{CD}^{+} \mathrm{CD}^{+} \mathrm{T}$-cells were more frequent
A i) Experimental design
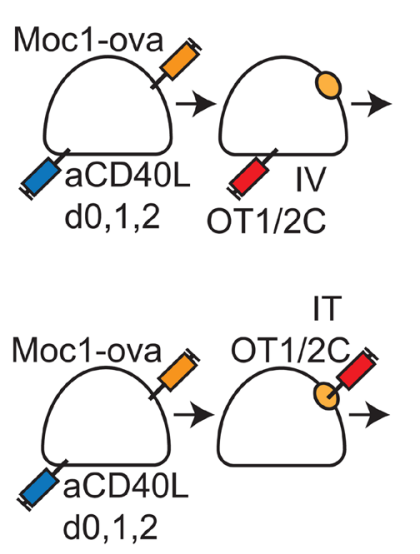

B i) Overall survival IV

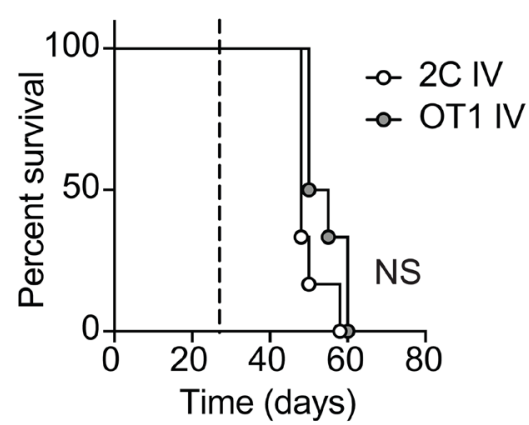

ii) IV T cell transfer

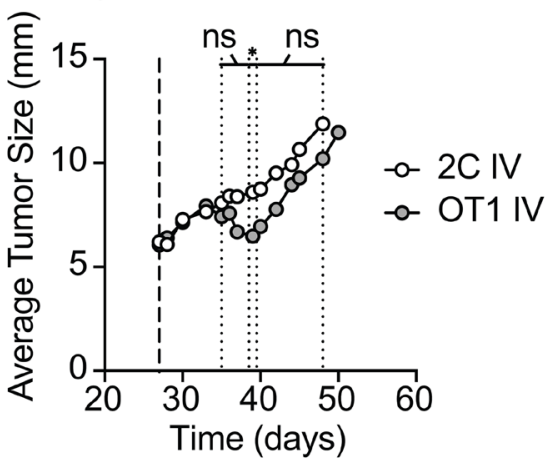

ii) Overall survival IT

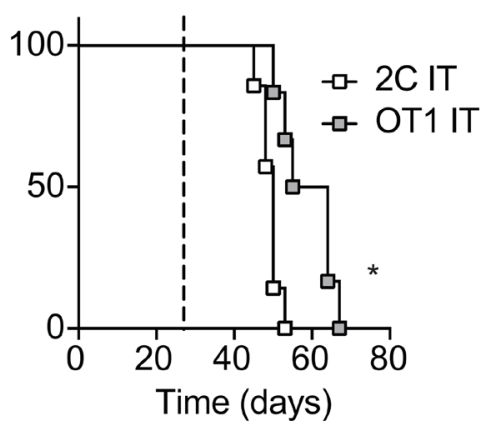

iii) IT biomaterial T cell transfer

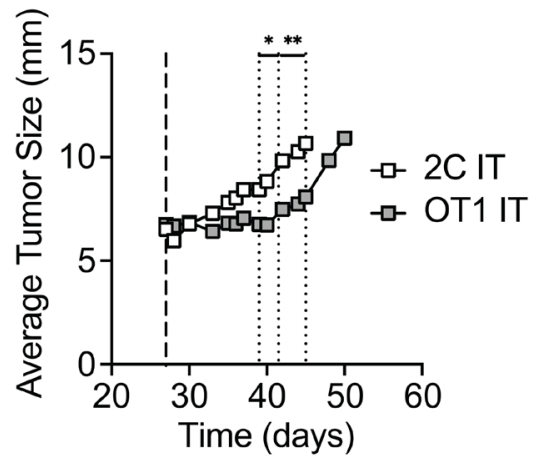

iii) Overall survival IV vs IT

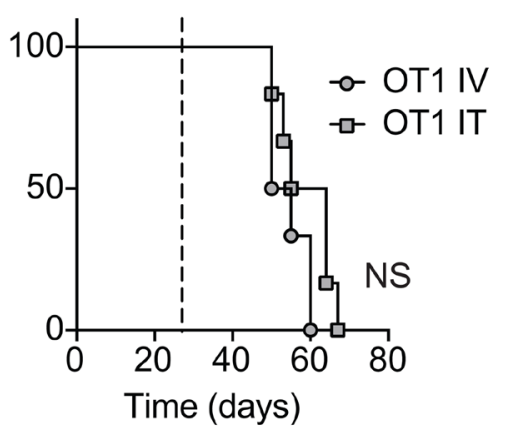

Figure 2: Tumor control following injection of antigen-specific T cell biomaterial. (A) (i) MOC1-ova tumors were established in immune competent $\mathrm{C} 57 \mathrm{BL} / 6$ mice along with anti-CD40L to block implantation-related immune responses, and randomized to receive intravenous (IV) or intratumoral (IT) adoptive T cell transfer to established tumors. Mice received $1 \times 10^{6}$ tumor-specific OT1 T-cells or non-specific 2C T-cells IV in suspension, or in $30 \mu \mathrm{l}$ of Matrigel into the tumor (IT). Graphs show (ii) tumor growth following IV transfer, or (iii) tumor growth following IT transfer. (B) Overall survival of groups treated as in (A), showing (i) IV treatment groups, and (ii) IT treatment groups. (iii) comparison of overall survival of mice treated with OT1 T cells IV versus IT. Experiments incorporated 6-8 mice per group and the displayed experiment is representative of 3 independent repeats. Abbreviation: NS: not significant. ${ }^{*} p<0.05,{ }^{* *} p<0.01$. 
in the OT1-injected samples (data not shown). FoxP3 ${ }^{+}$ and PD-L1 ${ }^{+}$cells did not differ substantially between the groups, as determined by multiplex IHC (Figure 4A). IHC analysis was not able to distinguish transferred T-cells from host T-cells in the tumor, so the matching specimens were analyzed by flow-cytometry for the transferred cells. As with the peripheral blood, infiltrating transferred cells were distinguished using congenic markers (Figure 4Bi). Representative flow-gating demonstrates the prominent OT1 T-cell population within the OT1-injected tumors, while the $2 \mathrm{C}$-injected tumors show a smaller population of 2C T-cells within the tumor (Figure 4Bi). Quantitative analysis of the flow-data revealed a higher amount of total $\mathrm{CD}^{+}$T-cells within the OT1-injected tumors ( $p=$ $0.09)$, and the increase was mostly made up of OT1 cells $(p<0.05)$ (Figure 4Bii). Conversely, the 2C-injected tumors showed a low proportion of $2 \mathrm{C}$ T-cells within the $\mathrm{CD}^{+} \mathrm{T}$-cell population infiltrating the tumor. These data demonstrate that OT1 T-cells represented the majority of $\mathrm{CD}^{+}$T-cells infiltrating the tumors, and reveal

A i) Experiment design

ii) Transferred T cell gating and phenotyping
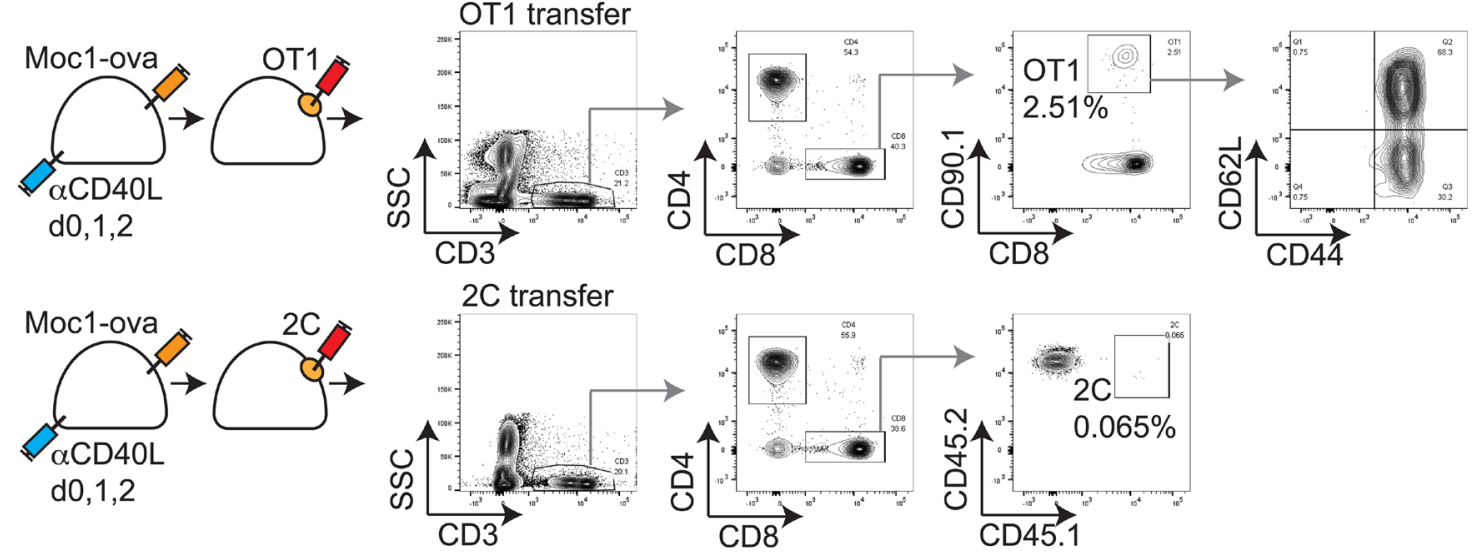

B
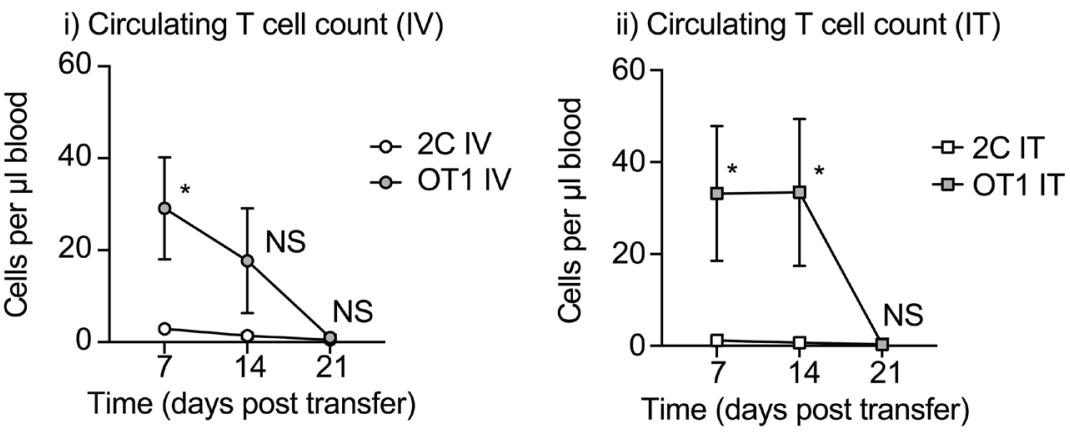

C

i) IV OT1 differentiation

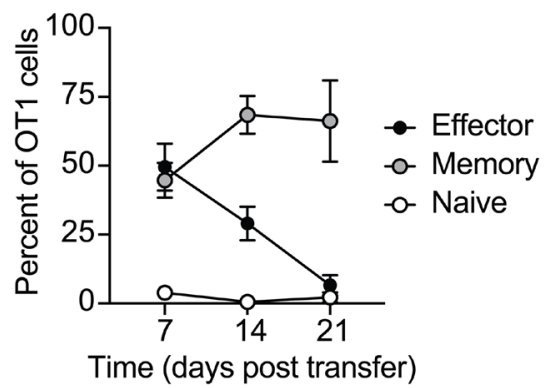

ii) IT OT1 differentiation

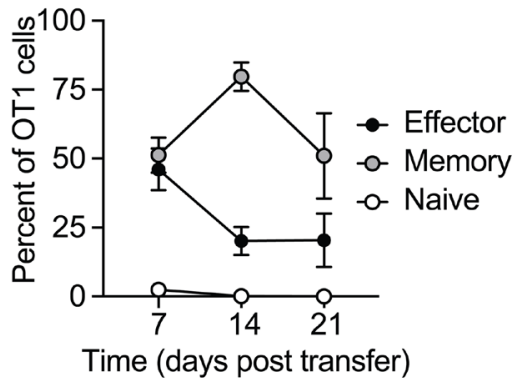

Figure 3: Characterization of circulating T-cells following biomaterial injection. (A) (i) MOC1-ova tumors were established in immune competent C57BL/6 mice and randomized to receive intravenous (IV) or intratumoral (IT) adoptive T-cell transfer. Mice received $1 \times 10^{6}$ tumor-specific OT1 T-cells or non-specific 2C T-cells IV in suspension, or in $30 \mu 1$ of Matrigel into the tumor (IT). (ii) Representative flow cytometry plots show whole blood 14 days following adoptive T-cell transfer showing identification of CD3+CD8+CD90.1+ OT1 T cells or CD3+CD8+CD45.2+2C T-cells. (B) Quantitative analysis of the number of OT1 T-cells and 2C T-cells in the peripheral blood over time following transfer (i) IV as a suspension or (ii) IT as a biomaterial. Phenotypic analysis of Effector (CD44+CD62L-, Memory (CD44+CD62L+), or Naive (CD44-CD62L+) among gated OT1 T-cells over time following transfer (i) IV as a suspension, or (ii) IT as a biomaterial. (C) Phenotypic analysis of Effector (CD44+CD62L-, Memory (CD44+CD62L+), or Naive (CD44-CD62L+) among gated OT1 T-cells over time following transfer (i) IV as a suspension, or (ii) IT as a biomaterial. Abbreviation: NS: not significant, ${ }^{*} p<0.05$. 
antigen-specific expansion and successful disruption of the tumor immune environment.

To determine whether antigen-specific T-cell transfer impacted the broader immune environment of the tumor, we analyzed the infiltration of the major myeloid populations in the tumor (Figure 4Ci). Neutrophils represent the largest single infiltrating immune population in these tumors, and these were significantly decreased in number following the introduction of antigen-specific
OT1 T-cells in the biomaterial $(p<0.001)$ (Figure 4Cii). There was no significant difference in the proportion of tumor-associated macrophages (TAM's) or monocytes (Figure 4Cii), or in the small population of dendritic cells (not shown), though it remains possible that the differentiation of these cells was impacted. These data clearly show that the injection of OT1 T-cell biomaterial brought a major change of the tumor immune environment, with contrasting effects on the proportions of $\mathrm{CD}^{+} \mathrm{T}$-cells

A $2 \mathrm{C}$ biomaterial

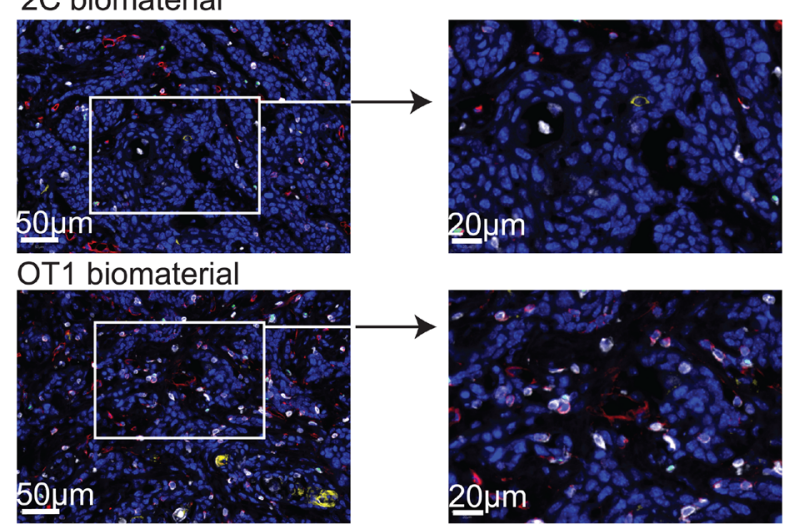

B i) T cell gating
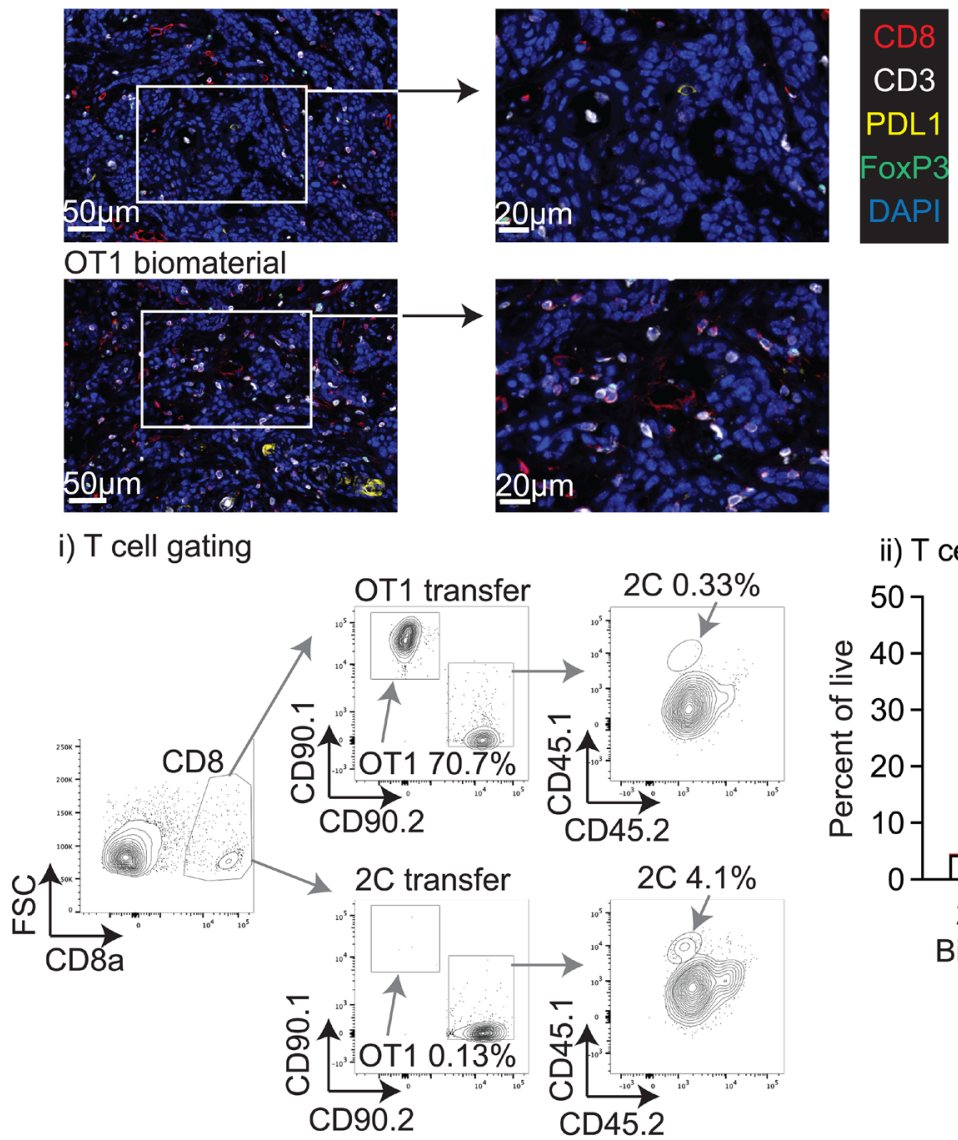

C i) Myeloid gating

ii) Myeloid cells in tumors
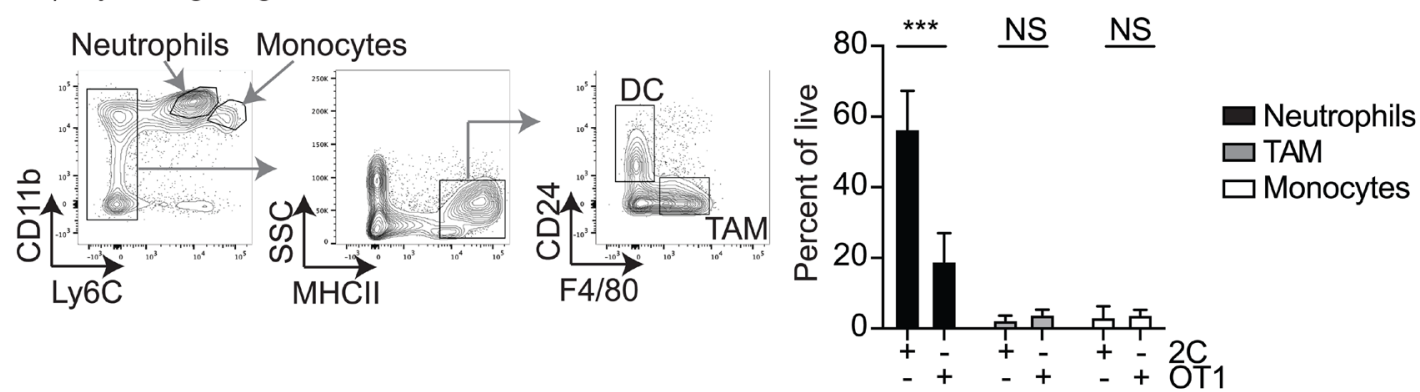

Figure 4: Characterization of the tumor environment following biomaterial injection. MOC1-ova tumors were established in immune competent $\mathrm{C} 57 \mathrm{BL} / 6$ mice and randomized to receive $1 \times 10^{6}$ tumor-specific OT1 T-cells or non-specific $2 \mathrm{C}$ T-cells in $30 \mu \mathrm{l}$ of Matrigel into the tumor. Tumors were harvested 7 days later for analysis of infiltrating immune cells. (A) Representative images following multiplex IHC for infiltrating immune cells in the tumor following injection of 2C or OT1 biomaterial. (B) (i) Identification of congenic CD90.1+CD90.2- OT1 and CD90.2+CD45.1+ 2C in the tumor from infiltrating CD8 T-cells. (ii) Graph of mean and standard deviation of infiltrating CD8 T-cells and the proportion that are host, transferred OT1, or transferred 2C. (C) (i) Representative flow cytometry plots show gating for major myeloid populations in the tumor. (ii) Proportions of Neutrophils, TAM, and monocytes in tumors treated with $2 \mathrm{C}$ or OT1 biomaterials Abbreviation: NS: not significant. ${ }^{*} p<0.05,{ }^{* * *} p<0.001$. 
and neutrophils, and exhibiting a high infiltration of the injected OT1 T-cells. However, despite these positive changes, T-cell transfer was not sufficient to induce a long-lasting tumor control.

\section{T-cell biomaterial control of recurrence following surgical resection}

Successful T-cell killing of targets can be highly impacted by effector to target ratios, and so may be much more effective in minimal residual disease settings. Our primary goal is to develop approaches that prevent local recurrence following surgical resection, and biomaterial delivery of T-cells may be optimal to drive locoregional immunity via treatment of the resection cavity. To model this, we made use of a tumor resection model that results in consistent local recurrence that is treatable via immunotherapy [9, 12]. Moc1-ova tumors were established in immune-competent C57BL/6 mice and mice that were randomized to no-surgery or subtotal resection of the tumor. Mice were further randomized to receive biomaterials loaded with tumor-specific OT1 T-cells or non-specific 2C T-cells, either delivered intratumorally in the non-resection group as before, or into the resection cavity (Figure 5Ai). Mice were followed for tumor growth, recurrence following surgery, and overall survival. As expected, surgical resection led to a tumor-free period followed by rapid local recurrence (Figure 5Aii). Administration of antigen-specific T-cells into the resection cavity significantly delayed recurrence $(p<0.01)$ (Figure 5Aiii), and led to a significant increase in overall survival $(p<0.01)$. However, all tumors recurred and the combination of T-cell transfer and tumor resection, while superior to direct injection into unresected tumors, did not result in tumor cure (Figure 5Aiv). Therefore, despite the benefit in locally administering T-cell biomaterial into the resection cavity, all the groups eventually failed.

In tumors, exhaustion of tumor-specific T-cells is commonly observed and can be overcome through the administration of checkpoint inhibitors. To determine whether failure of local control is a result of T-cell exhaustion, MOC1-ova tumors were established in the same manner and all mice underwent subtotal resection of the tumor followed by immediate application of tumorspecific or non-specific T-cell biomaterials into the resection cavity. Mice were also randomized to receive 3 doses of $250 \mu \mathrm{g}$ PD1-antibody at days 5, 12, and 19 after resection (Figure 5B). As before, antigen-specific T-cell transfer significantly delayed tumor recurrence (OT1 vs. 2C $p<0.01$ ), though all mice recurred (Figure 5Bii-v). Anti-PD1 treatment did not impact recurrence or survival in the absence of antigen-specific T-cell transfer (2C vs. 2C+anti-PD1, median survival 70 vs. 74 days, respectively), consistent with data showing that preexisting immune responses in tumors are essential to the success of checkpoint inhibitors [20, 21]. Importantly, administration of anti-PD1 significantly delayed recurrence in mice treated with antigen-specific T-cells in the biomaterial (OT1+anti-PD1 median survival 110 days, $p<0.05$ vs. $2 \mathrm{C}+$ anti-PD1 median survival 74 days, $p<$ 0.05 vs. OT 1 median survival 84 days), and this resulted in long-term tumor cures (Figure $5 \mathrm{Biv}-\mathrm{v}$ ). These data emphasize that biomaterial delivery of tumor antigenspecific T-cells significantly delays local recurrence and that the addition of adjuvant PD1-blockade can prevent local recurrence and permit tumor cures. We propose that this is a potential intervention for HNSCC patients with poor pre-existing anti-tumor immunity with a high risk of local recurrence, who are currently poorly served by existing treatment options.

\section{DISCUSSION}

Our data demonstrate that local administration of T-cells into a biomaterial preserves T-cell function invitro and in-vivo. By using a biomaterial that forms to the resection cavity we can deliver T-cells locally following surgery, retain T-cell function, and delay tumor recurrence. We show that adjuvant anti-PD1 is ineffective following surgery in mice that lack pre-existing anti-tumor immunity, but tumor antigen-specific T-cell transfer combines with anti-PD1 to prevent local recurrence and cure a subset of mice.

Our model uses treatment with anti-CD40L at tumor implantation to eliminate pre-existing immune responses to the tumor. Injection of cancer cells in suspension has long been known to generate anti-tumor immune responses $[22,23]$, and this can lead to spontaneous rejection of highly immunogenic tumors [23, 24]. We recently demonstrated that anti-CD40L prevented the generation of resident memory phenotype T-cells [19], which are highly impactful to the outcome of patients with HNSCC following treatment conventional therapies [25]. By using anti-CD40L at tumor implantation, we generate tumors with low numbers of T-resident memory CD8 ${ }^{+} \mathrm{T}$-cells, and we would expect a poor response to checkpoint inhibitors in these animals as observed in patients [26]. Importantly, we demonstrate that local adoptive transfer of tumor antigen-specific T-cells can overcome the lack of pre-existing immunity and allow effective combination with checkpoint inhibitors to control residual disease. Expression of the SIINFEKL peptide increases the baseline immunogenicity of the Moc1 cell line [27], which can result in long-term antigen specific protective immunity. However, while mice cured of tumors by implantation of OT1 T-cells and PD1 blockade remained tumor-free long-term, we did not test whether these mice could reject rechallenge with the Moc1-ova or the parental Moc1 cell line. It would be valuable to know that the therapy results in long-term survival of tumor-specific T-cells to ensure long-term protection against recurrence or control of previously undetected micrometastases. 
A i) Resection model

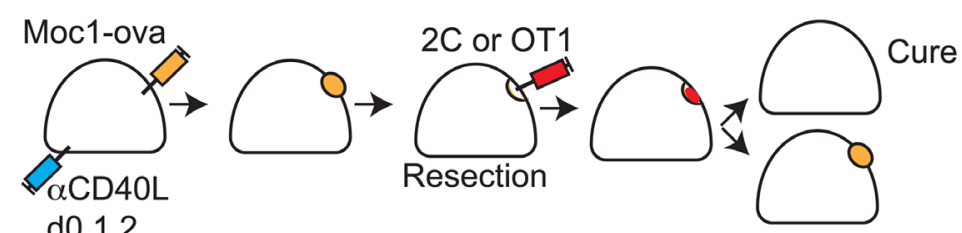

d0,1,2

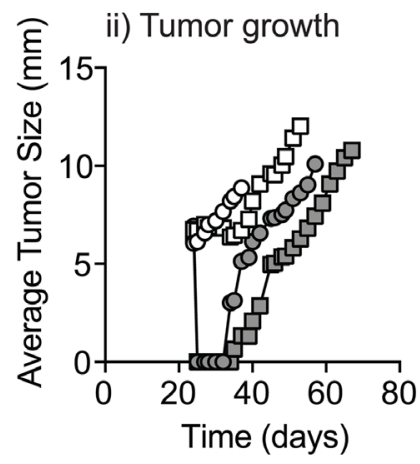

iii) Recurrence following resection

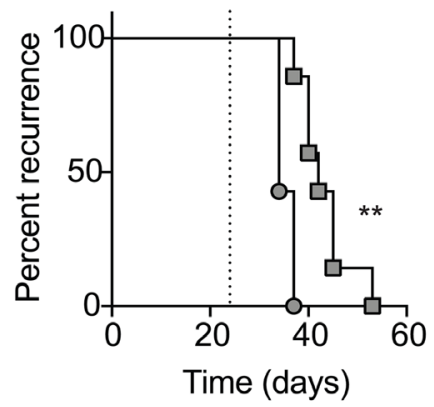

iv) Overall survival

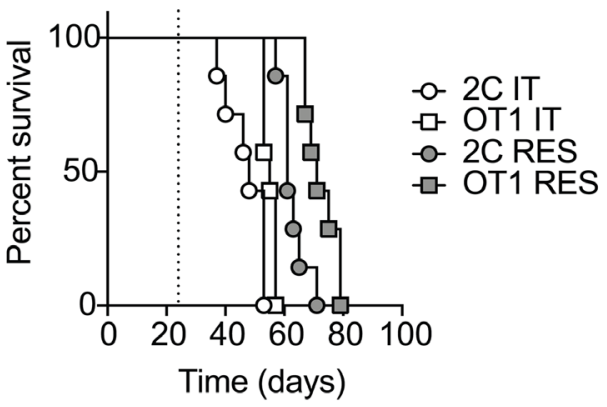

B i) Adjuvant immunotherapy resection model
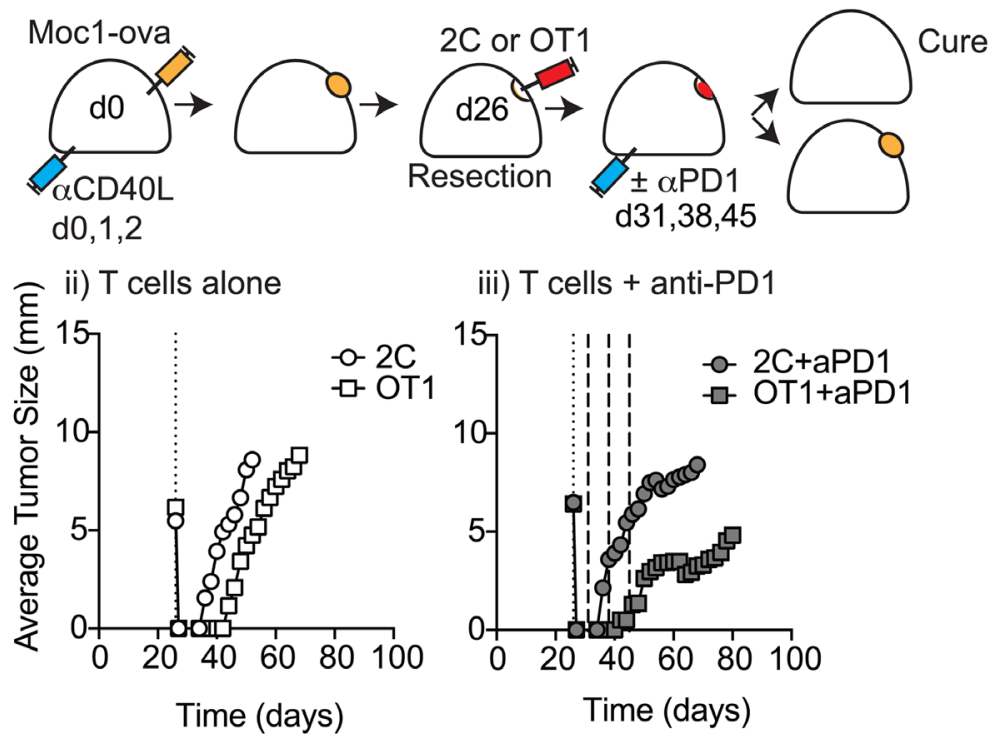

iii) T cells + anti-PD1
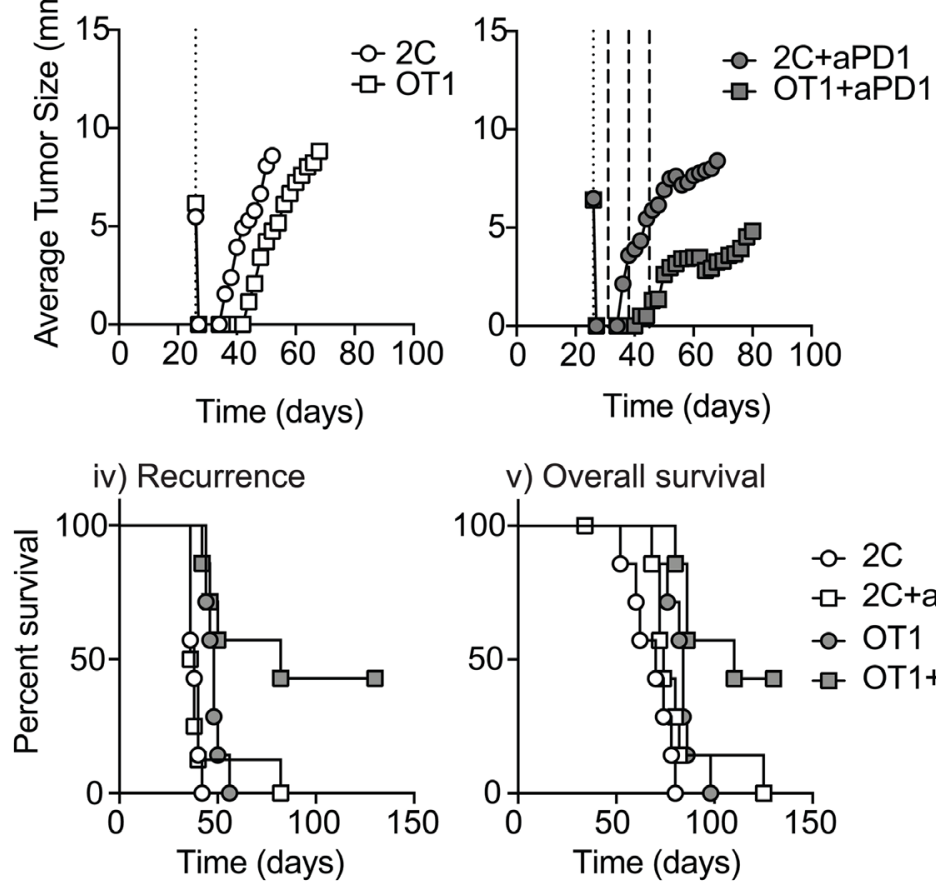

v) Overall survival

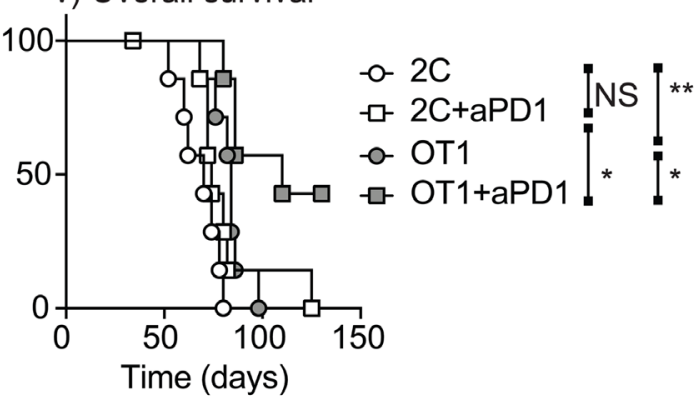

Figure 5: T-cell biomaterial control of recurrence following surgical resection. (A) (i) MOC1-ova tumors were established in immune competent C57BL/6 mice and underwent IT administration of tumor-specific OT1 T-cells or non-specific 2C T-cells in $30 \mu 1$ of Matrigel into the tumor, or subcomplete resection and administration of the same biomaterials into the resection cavity. Graphs show (ii) average tumor size for all groups (iii) recurrence for resection groups, and (iv) overall survival of all treated mice. (B) (i) Immune competent mice bearing MOC1-ova tumors underwent surgical resection and administration of $\mathrm{T}$ cell biomaterials into the resection cavity as per a). Mice were randomized to receive no further treatment or 3 weekly doses of adjuvant anti-PD1 starting $5 \mathrm{~d}$ following resection. Graphs show average tumor size for (ii) T-cells alone or (iii) T-cells plus adjuvant anti-PD1. Graphs show (iv) recurrence following resection, and (v) overall survival of treated mice. Abbreviation: NS: not significant. ${ }^{*} p<0.05,{ }^{* *} p<0.01$. 
Currently, adoptive T-cell therapy for HNSCC and other cancers is administered intravenously, and this is critical for patients with metastatic cancer since the tumors may be widespread. However, systemic delivery of T-cells still necessitates multiple steps for functional tumor control. Adoptive transfer of T-cells requires in-vivo antigen-specific expansion following transfer [6,7], which may present a problem following surgical resection. We have previously demonstrated that the capacity for T-cell expansion in tumor-draining lymph nodes is rapidly lost following resection [9]. This can be overcome through a combination of lymphodepletion prior to transfer which drives homeostatic T-cell expansion [28], and post-transfer antigen-specific vaccination [29]. The combination of these treatments results in the expansion of memory phenotype T-cells that are more effective in tumor control [30]. We propose that locoregional therapy to the resection site can take advantage of residual tumor antigen to permit expansion of both effector and memory cells without the need to lymphodeplete the patient or prepare a patientspecific vaccine. Importantly, we demonstrate that tumor-specific cells expand in number in the peripheral circulation and accumulate at the tumor, indicating that lymphocyte recirculation is fully functional when T-cells are delivered to the resection site. Recirculation is critical to effectively detect tumors that may additionally be present at distant sites, and sustain systemic anti-tumor immunity [10].

Biomaterial delivery is logical for delivery to the resection site, which may be highly disrupted and highly variable between patients. Our approach used a simple biomaterial for rapid release of the T-cells; however, this approach can be refined to include additional agents to support T-cell activation and expansion [16, 17] and modified to control T-cell release kinetics. Importantly, when T-cells were delivered locally in a biomaterial, there was no negative impact on their numbers in the systemic circulation, suggesting that this platform has the potential to provide systemic immunosurveillance for distant disease. Further studies are necessary to map the activation and distribution pattern of the T-cells to understand the effect of local delivery on activation in the local site versus draining lymphatics, and the effect of this therapy on recirculation kinetics [10]. In HNSCC, resection of the advanced tumor, followed by adjuvant therapy, will fail in approximately half of the patients, with $20-30 \%$ of patients failing locally [31, 32]. Therefore, locoregional T-cell delivery may be an effective tool to generate improved anti-tumor immunosurveillance both within and outside the primary tumor site - an important feature for HNSCC management.

In our preclinical model, we were able to source large numbers of tumor antigen-specific T-cells from congenic TCR transgenic mice. In patients, sourcing these cells will be a much more significant problem. Traditionally, T-cells for adoptive transfer are generated by cytokine-driven in-vitro expansion using tumor fragments obtained from a resected tumor [33]. In patients with widely metastatic melanoma a surgically accessible tumor can provide the tissue to expand tumor-specific T-cells, but there may not be equivalent opportunities that fit with current surgical management of HNSCC. Recent advancements in tumor antigen identification using genomic analysis of patient-specific tumor mutations have permitted in-vitro expansion of highly selective T-cell clones for adoptive transfer [34-36], though at present these cells are still expanded from surgical material. If we are to administer these T-cells into the resection cavity immediately following surgery, alternative sources of tumor-specific T-cells will be necessary.

Together, these data demonstrate a potential therapy for patients with poorly infiltrated tumors with a high risk of recurrence following surgical resection. Further work is needed to develop a biomaterial for clinical translation. A range of potential biomaterial options are available for direct depot injection of immunotherapies alone, or in surgical settings (reviewed in $[11,37,38]$ ). In addition, it will be valuable to evaluate additional components to support T-cells and control the local inflammatory environment to maximize T-cell control of residual disease.

\section{MATERIALS AND METHODS}

\section{Ethics}

All animal protocols were approved by the Earle A. Chiles Research Institute IACUC (Animal Welfare Assurance No. A3913-01).

\section{Animals and cell-lines}

6 to 8-week-old female $\mathrm{C} 57 \mathrm{BL} / 6$ mice were obtained from The Jackson Laboratory. Survival experiments were performed with 6-8 mice per experimental group, and mechanistic experiments with 4-5 mice per group. The Moc1 murine HNSCC cell-line was kindly provided by Dr. Uppaluri (Dana Faber Cancer Institute, MA) [39]. A plasmid encoding a fusion protein of GFP with a C-terminal OVA $_{257-264}$ (SIINFEKL) tag to ensure non-secreted cytoplasmic expression of the model antigen has been previously described [19]. Moc1 cells were transfected with the GFP-SIINFEKL construct and $\mathrm{GFP}^{+}$cells were sorted by flow cytometry to generate a stable $\mathrm{GFP}^{+}$population. Presentation of SIINFEKL was confirmed using a B3Z T-cell assay [40], with Moc1-ova or control cells seeded with B3Z T-cells, and antigen-specific recognition confirmed by $\beta$-gal assay. Species identity checks on these murine cell lines were performed with murine-specific MHC antibodies, and were tested for contamination within the past 6 months using a Mycoplasma Detection Kit (SouthernBiotech, 
Birmingham, Alabama). 2C-mice transgenic for a TCR recognizing the model antigen SIYRYYGL were kindly provided by Dr. Gajewski (University of Chicago, Chicago, IL). OT1-transgenic mice were gifted by Dr. Redmond (Earle A. Chiles Research Institute). For in-vitro culture or adoptive transfer, spleens from these mice were harvested and $\mathrm{CD}^{+}$T-cells were isolated using EasySep kit (Stemcell Technologies, Vancouver, Canada).

\section{Antibodies and reagents}

Flow-cytometry antibodies included CD3e-PE, PD1-BV605, CD45-BV786 (BD-Biosciences), CD90.1FITC， CD62L-PECy7， CD45.1-APC， CD45.1-PE (eBioscience), CD45.2-Alexa700, CD-8 $\alpha$-Percp-Cy5.5, CD4-FITC, CD103-APC, CD24-APCcy7 (Invitrogen), CD44-APCy7, CD4-BV421, F4/80-PercpCy5.5, CD39PECy7, PDL1-PE, CD90.2-Alexa 700, MHCII-BV421, CD11b-BV650, Ly6C-BV711 (Biolegend), CD8 $\alpha-P E-$ Texas-red (Life Technologies, Carlsbad, CA, USA). Blocking PD-1 antibody (clone RMP1-14, BioXCell, Branford, CT, USA) was administered systemically by intraperitoneal injections of $250 \mu \mathrm{g}$ [41]. Blocking anti-CD40L (clone MR1, BioXCell) was administered systemically by intraperitoneal injections of $250 \mu \mathrm{g}$ [19].

\section{In-vitro T-cell viability and function}

Purified $\mathrm{CD}^{+}$T-cells from transgenic $2 \mathrm{C}$ or OT1 splenocytes were loaded into Matrigel (Corning Inc., Corning, NY, USA) to form $50 \mu$ pellets, each containing $1.5 \times 10^{5} \mathrm{CD}^{+}$T-cells. The pellets were seeded to Matrigel-coated plates and allowed to solidify at $37^{\circ} \mathrm{C}$ for 30 minutes before submersion in media. The number and viability of cells were determined using ViaCount reagents (Luminex) according to manufacturer instructions. Viable and non-viable cells are distinguished using DNA-binding dyes and read on a Guava easyCyte (Luminex). The absolute cell numbers and percent viable cells were used to evaluate the release of viable $\mathrm{T}$ cells from Matrigel pellets. At each time-point 10 wells were analyzed for 10 pellets and 10 supernatants. To monitor antigen-specific control of cancer-cells, tumor cells were plated, and purified $\mathrm{CD}^{+} \mathrm{T}$-cells from transgenic $2 \mathrm{C}$ or OT1 splenocytes were loaded into Matrigel to form $50 \mu \mathrm{l}$ pellets, each containing $1.5 \times 10^{5} \mathrm{CD}^{+} \mathrm{T}$-cells as described. The pellets were seeded to cancer-cells coated plates and imaged using Incucyte (Sartorius, Goettingen, Germany).

\section{In-vivo models}

Tumors were inoculated subcutaneously into immune-competent female mice at a dose of $5 \times 10^{6}$ Moc1-ova cells, and three doses of $100 \mu \mathrm{g}$ anti-CD40L were administered at days 0,1 , and 2 to eliminate the immune response at tumor challenge and establish poorly infiltrated tumors [19]. Prior studies have demonstrated that all effects of anti-CD40L are lost within 14 days [19]. Tumors were allowed to develop to $6-8 \mathrm{~mm}$ in diameter over 20-30 days, at which point the mice were administered with $1 \times 10^{6} \mathrm{~T}$-cells. In the intravenous (IV) model, OT1 or 2C cells were delivered in $100 \mu \mathrm{l}$ of PBS; in the intratumoral (IT) model, OT1 or $2 \mathrm{C}$ cells were suspended in Matrigel mixed 1:1 with PBS and a total volume of $30 \mu \mathrm{l}$ was injected intratumoraly; in the subtotal resection model, following surgical skin prep, an incision was made over the tumor and the encapsulated tumor was mechanically detached from the skin. The tumor capsule attached to the underlying fascia was left in place and the upper portion of the tumor resected, leaving 2-2.5 mm depth of tumor in the resection cavity, and $30 \mu \mathrm{l}$ of the above-mentioned mixture with $1 \times 10^{6} \mathrm{~T}$-cells was placed and allowed to solidify in the surgical site. Mice that were randomized into adjuvant immunotherapy group received three doses of intraperitoneal $250 \mu \mathrm{g}$ PD- 1 antibody in 100 $\mu 1$ of PBS, 5, 12, and 19 days post-operatively.

\section{Flow-cytometry}

For analysis of circulating tumor-specific T-cells, whole-blood samples were collected at designated timepoints, and whole blood was surface stained for phenotypic markers, and counting beads were included to permit quantitative analysis of circulating cells [19]. The mixture of antibodies included CD3, CD4, CD8 $\alpha$, CD44, CD45.1, CD45.2, CD62L, and CD90.1, to distinguish circulating $\mathrm{CD}^{+} \mathrm{CD}^{+} \mathrm{CD} 90.1^{+} \mathrm{OT} 1 \mathrm{~T}$-cells and $\mathrm{CD}^{+} \mathrm{CD}^{+} \mathrm{CD}^{+} 5.1^{+}$ 2C T-cells from host-cells.

For analysis of tumor-infiltrating tumor-specific T-cells, tumors grown in C57BL/6 mice were harvested 7 days after treatment, and single-cell suspensions were prepared by using a gentleMACS dissociator (Miltenyi Biotech, Bergisch Gladbach, Germany), followed by agitation in digest solution $(250 \mathrm{U} / \mathrm{mL}$ collagenase, $30 \mathrm{U} /$ $\mathrm{mL}$ DNase, $5 \mathrm{mM} \mathrm{CaCl}_{2}, 5 \% \mathrm{FBS}$ in HBSS in PBS) for 30 minutes at $37^{\circ} \mathrm{C}$. The digest was filtered through $100 \mu \mathrm{m}$ strainer to remove macroscopic debris. Cells were surfacestained with the phenotypic markers CD45.1, CD45.2, CD90.2, CD103, CD4, CD8, CD11b, MHCII, Ly6C, CD11b, CD24, F4/80, and a viability dye to distinguish

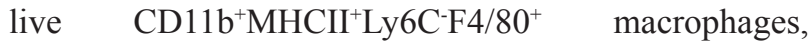
$\mathrm{CD} 11 \mathrm{~b}^{+} \mathrm{MHCII}-\mathrm{Ly} 6 \mathrm{C}^{+}$neutrophils, CD11b ${ }^{+} \mathrm{F} 4 / 80 \mathrm{Ly}^{-} \mathrm{CC}^{+}$

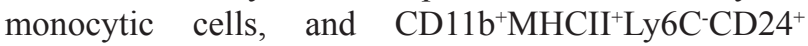
dendritic cells [42], as well as the adoptively transferred OT1 and 2C T-cells as described above. Samples were run on a BDIS Fortessa SORP or BDIS LSRII SORP (BD Biosciences) and analyzed using FloJo (Tree-Star, Ashland, OR, USA). Infiltrating cell proportions are shown as a percentage of live cells to control for varying degrees of overall infiltration in the tumors and permit direct comparisons between groups. 


\section{Multiplex IHC}

Tumors grown in C57BL/6 mice were harvested 7 days following treatment, zinc-fixed, sectioned and prepared as previously described [43]. Primary antibodies were anti-CD3 (SP7, Abcam, Cambridge, UK), anti-CD8 $\alpha$ (4SM15, eBioscience), anti-FoxP3 (FJK-16s, Invitrogen, Carlsbad, CA, USA), anti-PD-L1 (D5V3B, CellSignaling Technology, Danvers, MA, USA), and DAPI (Perkin Elmer). Anti-Rat HRP (mouse adsorbed) or AntiRabbit HRP secondary antibodies (Vector Laboratories) were used prior to tyramide staining with Opal 7-Color Automation IHC Kit (690 for CD3, 570 for PD-L1, 620 for $\mathrm{CD} 8 \alpha$, and 520 for FoxP3). Slides were scanned with Vectra Polaris (Perkin Elmer) and analyzed using QuPath 0.2.0-m4 [44].

\section{Statistical analysis}

Data were analyzed and graphed using Prism (GraphPad Software, La-Jolla, CA, USA). Individual data sets were compared using the two-tailed unpaired Student $t$-test; overall survival of groups was compared using the log-rank test for differences in Kaplan-Meier survival curves.

\section{Abbreviations}

HNSCC: head and neck squamous-cell carcinoma; PD1: programmed cell death protein 1; MOC: mouse oral cancer; ova: ovalbumin; IT: intratumoral; IV: intravenous; IHC: immunohistochemistry; TAM: tumor-associated macrophages; TCR: T-cell receptor.

\section{Author contributions}

Conceptualization: MJG, SS. Investigation: SS,JB, SB. Methodology: SS, SJ, MJG. Resources: MJG, MRC, RBB. Visualization: MJG. Writing: SS, MRC, MJG. Funding acquisition: SS, MJG, MRC. Supervison: MJG.

\section{CONFLICTS OF INTEREST}

MJG and MRC receive research funding from Bristol Myers-Squibb, Jounce, and Mavupharma that is unrelated to the content of this manuscript. The remaining authors declare no competing interests. Funders had no input in the content of the manuscript.

\section{FUNDING}

This work was supported by NCI R01CA182311, NCI R01CA244142 (MJG), NCI R01CA208644 (MRC), Israel Cancer Association (SS).

\section{REFERENCES}

1. Jones AS, Bin Hanafi Z, Nadapalan V, Roland NJ, Kinsella A, Helliwell TR. Do positive resection margins after ablative surgery for head and neck cancer adversely affect prognosis? A study of 352 patients with recurrent carcinoma following radiotherapy treated by salvage surgery. $\mathrm{Br}$ J Cancer. 1996; 74:128-32. https://doi.org/10.1038/ bjc.1996.327. [PubMed]

2. Bernier J, Cooper JS, Pajak TF, van Glabbeke M, Bourhis J, Forastiere A, Ozsahin EM, Jacobs JR, Jassem J, Ang KK, Lefèbvre JL. Defining risk levels in locally advanced head and neck cancers: a comparative analysis of concurrent postoperative radiation plus chemotherapy trials of the EORTC (\#22931) and RTOG (\# 9501). Head Neck. 2005; 27:843-50. https://doi.org/10.1002/hed.20279. [PubMed]

3. Hanna GJ, Adkins DR, Zolkind P, Uppaluri R. Rationale for neoadjuvant immunotherapy in head and neck squamous cell carcinoma. Oral Oncol. 2017; 73:65-69. https://doi. org/10.1016/j.oraloncology.2017.08.008. [ubMed]

4. Friedman J, Moore EC, Zolkind P, Robbins Y, Clavijo PE, Sun L, Greene S, Morisada MV, Mydlarz WK, Schmitt N, Hodge JW, Schreiber H, Van Waes C, et al. Neoadjuvant PD-1 Immune Checkpoint Blockade Reverses Functional Immunodominance among Tumor Antigen-Specific $\mathrm{T}$ Cells. Clin Cancer Res. 2020; 26:679-89. https://doi. org/10.1158/1078-0432.CCR-19-2209. [PubMed]

5. Hsueh EC, Gupta RK, Yee R, Leopoldo ZC, Qi K, Morton DL. Does endogenous immune response determine the outcome of surgical therapy for metastatic melanoma? Ann Surg Oncol. 2000; 7:232-38. https://doi.org/10.1007/ BF02523659. [PubMed]

6. Gattinoni L, Klebanoff CA, Palmer DC, Wrzesinski C, Kerstann K, Yu Z, Finkelstein SE, Theoret MR, Rosenberg SA, Restifo NP. Acquisition of full effector function in vitro paradoxically impairs the in vivo antitumor efficacy of adoptively transferred CD8 + T cells. J Clin Invest. 2005; 115:1616-26. https://doi.org/10.1172/JCI24480. [PubMed]

7. Klebanoff CA, Gattinoni L, Torabi-Parizi P, Kerstann K, Cardones AR, Finkelstein SE, Palmer DC, Antony PA, Hwang ST, Rosenberg SA, Waldmann TA, Restifo NP. Central memory self/tumor-reactive CD8+ T cells confer superior antitumor immunity compared with effector memory T cells. Proc Natl Acad Sci U S A. 2005; 102:957176. https://doi.org/10.1073/pnas.0503726102. [PubMed]

8. Klebanoff CA, Gattinoni L, Palmer DC, Muranski P, Ji Y, Hinrichs CS, Borman ZA, Kerkar SP, Scott CD, Finkelstein SE, Rosenberg SA, Restifo NP. Determinants of successful CD8+ T-cell adoptive immunotherapy for large established tumors in mice. Clin Cancer Res. 2011; 17:5343-52. https:// doi.org/10.1158/1078-0432.CCR-11-0503. [PubMed]

9. Gough MJ, Crittenden MR, Sarff M, Pang P, Seung SK, Vetto JT, Hu HM, Redmond WL, Holland J, Weinberg AD. Adjuvant therapy with agonistic antibodies to CD134 (OX40) increases local control after surgical or radiation 
therapy of cancer in mice. J Immunother. 2010; 33:798 809. https://doi.org/10.1097/CJI.0b013e3181ee7095. [PubMed]

10. Blair TC, Alice AF, Zebertavage L, Crittenden MR, Gough MJ. The Dynamic Entropy of Tumor Immune Infiltrates: The Impact of Recirculation, Antigen-Specific Interactions, and Retention on T Cells in Tumors. Front Oncol. 2021; 11:653625. https://doi.org/10.3389/fonc.2021.653625. [PubMed]

11. Gough MJ, Baird JR, Bell RB. Implantable biomaterials to provide local immunotherapy following surgical resection. Oncotarget. 2018; 9:37612-13. https://doi.org/10.18632/ oncotarget.26487. [PubMed]

12. Baird JR, Bell RB, Troesch V, Friedman D, Bambina S, Kramer G, Blair TC, Medler T, Wu Y, Sun Z, de Gruijl TD, van de Ven R, Leidner RS, et al. Evaluation of Explant Responses to STING Ligands: Personalized Immunosurgical Therapy for Head and Neck Squamous Cell Carcinoma. Cancer Res. 2018; 78:6308-19. https:// doi.org/10.1158/0008-5472.CAN-18-1652. [PubMed]

13. Park CG, Hartl CA, Schmid D, Carmona EM, Kim HJ, Goldberg MS. Extended release of perioperative immunotherapy prevents tumor recurrence and eliminates metastases. Sci Transl Med. 2018; 10:eaar1916. https://doi. org/10.1126/scitranslmed.aar1916. [PubMed]

14. Monette A, Ceccaldi C, Assaad E, Lerouge S, Lapointe R. Chitosan thermogels for local expansion and delivery of tumor-specific $\mathrm{T}$ lymphocytes towards enhanced cancer immunotherapies. Biomaterials. 2016; 75:237-49. https:// doi.org/10.1016/j.biomaterials.2015.10.021. [PubMed]

15. Weiden J, Voerman D, Dölen Y, Das RK, van Duffelen A, Hammink R, Eggermont LJ, Rowan AE, Tel J, Figdor CG. Injectable Biomimetic Hydrogels as Tools for Efficient $\mathrm{T}$ Cell Expansion and Delivery. Front Immunol. 2018; 9:2798. https://doi.org/10.3389/fimmu.2018.02798. [PubMed]

16. Smith TT, Moffett HF, Stephan SB, Opel CF, Dumigan AG, Jiang X, Pillarisetty VG, Pillai SPS, Wittrup KD, Stephan MT. Biopolymers codelivering engineered T cells and STING agonists can eliminate heterogeneous tumors. J Clin Invest. 2017; 127:2176-91. https://doi.org/10.1172/ JCI87624. [PubMed]

17. Stephan SB, Taber AM, Jileaeva I, Pegues EP, Sentman CL, Stephan MT. Biopolymer implants enhance the efficacy of adoptive T-cell therapy. Nat Biotechnol. 2015; 33:97-101. https://doi.org/10.1038/nbt.3104. [PubMed]

18. Zebertavage LK, Alice A, Crittenden MR, Gough MJ. Transcriptional Upregulation of NLRC5 by Radiation Drives STING- and Interferon-Independent MHC-I Expression on Cancer Cells and T Cell Cytotoxicity. Sci Rep. 2020; 10:7376. https://doi.org/10.1038/s41598-02064408-3. [PubMed]

19. Crittenden MR, Zebertavage L, Kramer G, Bambina S, Friedman D, Troesch V, Blair T, Baird JR, Alice A, Gough MJ. Tumor cure by radiation therapy and checkpoint inhibitors depends on pre-existing immunity. Sci Rep.
2018; 8:7012. https://doi.org/10.1038/s41598-018-25482-w. [PubMed]

20. Spranger S, Koblish HK, Horton B, Scherle PA, Newton R, Gajewski TF. Mechanism of tumor rejection with doublets of CTLA-4, PD-1/PD-L1, or IDO blockade involves restored IL-2 production and proliferation of CD8(+) T cells directly within the tumor microenvironment. J Immunother Cancer. 2014; 2:3. https://doi.org/10.1186/2051-1426-2-3. [PubMed]

21. Chow MT, Ozga AJ, Servis RL, Frederick DT, Lo JA, Fisher DE, Freeman GJ, Boland GM, Luster AD. Intratumoral Activity of the CXCR3 Chemokine System Is Required for the Efficacy of Anti-PD-1 Therapy. Immunity. 2019; 50:1498-512.e5. https://doi.org/10.1016/j. immuni.2019.04.010. [PubMed]

22. North RJ, Bursuker I. Generation and decay of the immune response to a progressive fibrosarcoma. I. Ly-1+2suppressor T cells down-regulate the generation of Ly-1-2+ effector T cells. J Exp Med. 1984; 159:1295-311. https:// doi.org/10.1084/jem.159.5.1295. [PubMed]

23. Spiotto MT, Yu P, Rowley DA, Nishimura MI, Meredith SC, Gajewski TF, Fu YX, Schreiber H. Increasing tumor antigen expression overcomes "ignorance" to solid tumors via crosspresentation by bone marrow-derived stromal cells. Immunity. 2002; 17:737-47. https://doi.org/10.1016/s10747613(02)00480-6. [PubMed]

24. Shankaran V, Ikeda H, Bruce AT, White JM, Swanson PE, Old LJ, Schreiber RD. IFNgamma and lymphocytes prevent primary tumour development and shape tumour immunogenicity. Nature. 2001; 410:1107-11. https://doi. org/10.1038/35074122. [PubMed]

25. Duhen T, Duhen R, Montler R, Moses J, Moudgil T, de Miranda NF, Goodall CP, Blair TC, Fox BA, McDermott JE, Chang SC, Grunkemeier G, Leidner R, et al. Co-expression of CD39 and CD103 identifies tumor-reactive CD8 T cells in human solid tumors. Nat Commun. 2018; 9:2724. https:// doi.org/10.1038/s41467-018-05072-0. [PubMed]

26. Edwards J, Wilmott JS, Madore J, Gide TN, Quek C, Tasker A, Ferguson A, Chen J, Hewavisenti R, Hersey P, Gebhardt T, Weninger W, Britton WJ, et al. CD103+ Tumor-Resident CD8+ T Cells Are Associated with Improved Survival in Immunotherapy-Naïve Melanoma Patients and Expand Significantly During Anti-PD-1 Treatment. Clin Cancer Res. 2018; 24:3036-45. https://doi.org/10.1158/1078-0432. CCR-17-2257. [PubMed]

27. Medler TR, Blair TC, Crittenden MR, Gough MJ. Defining Immunogenic and Radioimmunogenic Tumors. Front Oncol. 2021; 11:667075. https://doi.org/10.3389/ fonc.2021.667075. [PubMed]

28. Goldrath AW, Bogatzki LY, Bevan MJ. Naive T cells transiently acquire a memory-like phenotype during homeostasis-driven proliferation. J Exp Med. 2000; 192:55764. https://doi.org/10.1084/jem.192.4.557. [PubMed]

29. Hu HM, Poehlein CH, Urba WJ, Fox BA. Development of antitumor immune responses in reconstituted lymphopenic hosts. Cancer Res. 2002; 62:3914-19. [PubMed] 
30. Dudley ME, Wunderlich JR, Yang JC, Hwu P, Schwartzentruber DJ, Topalian SL, Sherry RM, Marincola FM, Leitman SF, Seipp CA, Rogers-Freezer L, Morton KE, Nahvi A, et al. A phase I study of nonmyeloablative chemotherapy and adoptive transfer of autologous tumor antigen-specific $\mathrm{T}$ lymphocytes in patients with metastatic melanoma. J Immunother. 2002; 25:243-51. https://doi. org/10.1097/00002371-200205000-00007. [PubMed]

31. Cooper JS, Pajak TF, Forastiere AA, Jacobs J, Campbell BH, Saxman SB, Kish JA, Kim HE, Cmelak AJ, Rotman M, Machtay M, Ensley JF, Chao KS, et al, and Radiation Therapy Oncology Group 9501/Intergroup. Postoperative concurrent radiotherapy and chemotherapy for highrisk squamous-cell carcinoma of the head and neck. N Engl J Med. 2004; 350:1937-44. https://doi.org/10.1056/ NEJMoa032646. [PubMed]

32. Bernier J, Domenge C, Ozsahin M, Matuszewska K, Lefèbvre JL, Greiner RH, Giralt J, Maingon P, Rolland F, Bolla M, Cognetti F, Bourhis J, Kirkpatrick A, et al, and European Organization for Research and Treatment of Cancer Trial 22931. Postoperative irradiation with or without concomitant chemotherapy for locally advanced head and neck cancer. N Engl J Med. 2004; 350:1945-52. https://doi.org/10.1056/NEJMoa032641. [PubMed]

33. Dudley ME, Rosenberg SA. Adoptive cell transfer therapy. Semin Oncol. 2007; 34:524-31. https://doi.org/10.1053/j. seminoncol.2007.09.002. [PubMed]

34. Tran E, Robbins PF, Rosenberg SA. 'Final common pathway' of human cancer immunotherapy: targeting random somatic mutations. Nat Immunol. 2017; 18:255-62. https://doi.org/10.1038/ni.3682. [PubMed]

35. Tran E, Robbins PF, Lu YC, Prickett TD, Gartner JJ, Jia L, Pasetto A, Zheng Z, Ray S, Groh EM, Kriley IR, Rosenberg SA. T-Cell Transfer Therapy Targeting Mutant KRAS in Cancer. N Engl J Med. 2016; 375:2255-62. https://doi. org/10.1056/NEJMoa1609279. [PubMed]

36. Cohen CJ, Gartner JJ, Horovitz-Fried M, Shamalov K, Trebska-McGowan K, Bliskovsky VV, Parkhurst MR, Ankri C, Prickett TD, Crystal JS, Li YF, El-Gamil M, Rosenberg SA, Robbins PF. Isolation of neoantigen-specific T cells from tumor and peripheral lymphocytes. J Clin Invest. 2015; 125:3981-91. https://doi.org/10.1172/JCI82416. [PubMed]
37. Li J, Luo Y, Li B, Xia Y, Wang H, Fu C. Implantable and Injectable Biomaterial Scaffolds for Cancer Immunotherapy. Front Bioeng Biotechnol. 2020; 8:612950. https://doi. org/10.3389/fbioe.2020.612950. [PubMed]

38. Lei K, Tang L. Surgery-free injectable macroscale biomaterials for local cancer immunotherapy. Biomater Sci. 2019; 7:733-49. https://doi.org/10.1039/c8bm01470a. [PubMed]

39. Judd NP, Winkler AE, Murillo-Sauca O, Brotman JJ, Law JH, Lewis JS Jr, Dunn GP, Bui JD, Sunwoo JB, Uppaluri R. ERK1/2 regulation of CD44 modulates oral cancer aggressiveness. Cancer Res. 2012; 72:365-74. https://doi. org/10.1158/0008-5472.CAN-11-1831. [PubMed]

40. Sanderson S, Shastri N. LacZ inducible, antigen/MHCspecific $\mathrm{T}$ cell hybrids. Int Immunol. 1994; 6:369-76. https://doi.org/10.1093/intimm/6.3.369. [PubMed]

41. Friedman D, Baird JR, Young KH, Cottam B, Crittenden MR, Friedman S, Gough MJ, Newell P. Programmed cell death-1 blockade enhances response to stereotactic radiation in an orthotopic murine model of hepatocellular carcinoma. Hepatol Res. 2017; 47:702-14. https://doi.org/10.1111/ hepr.12789. [PubMed]

42. Blair TC, Bambina S, Alice AF, Kramer GF, Medler TR, Baird JR, Broz ML, Tormoen GW, Troesch V, Crittenden MR, Gough MJ. Dendritic Cell Maturation Defines Immunological Responsiveness of Tumors to Radiation Therapy. J Immunol. 2020; 204:3416-24. https://doi. org/10.4049/jimmunol.2000194. [PubMed]

43. Feng Z, Jensen SM, Messenheimer DJ, Farhad M, Neuberger M, Bifulco CB, Fox BA. Multispectral Imaging of $\mathrm{T}$ and $\mathrm{B}$ Cells in Murine Spleen and Tumor. J Immunol. 2016; 196:3943-50. https://doi.org/10.4049/ jimmunol.1502635. [PubMed]

44. Bankhead P, Loughrey MB, Fernández JA, Dombrowski Y, McArt DG, Dunne PD, McQuaid S, Gray RT, Murray LJ, Coleman HG, James JA, Salto-Tellez M, Hamilton PW. QuPath: Open source software for digital pathology image analysis. Sci Rep. 2017; 7:16878. https://doi.org/10.1038/ s41598-017-17204-5. [PubMed] 